\title{
Using a Fixed-Bed of Wheat Straw-Derived Biochar to Enhance Cracking of a Mixture of Four Pyrolysis Vapor Model Compounds
}

\author{
Christian Di Stasi, Darío Alvira, Belén González, Joan J. Manyà \\ Biochar Research Lab, Thermochemical Processes Research Group (GPT), \\ Aragón Institute of Engineering Research (I3A), \\ Technological College of Huesca, University of Zaragoza, Spain. \\ Tel. +34-974239320, e-mail: christiandistasi@unizar.es
}

\begin{abstract}
The aim of this work is to test the capacity of a biochar-based porous material to enhance the cracking of pyrolysis vapors. Biochar is a sustainable material obtained from renewable resources and a relatively low cost alternative to the metal-containing catalysts used in catalytic cracking.
\end{abstract}

\section{Background}

The biochar studied in this work was obtained from the slow pyrolysis of wheat straw at a peak temperature of $500^{\circ} \mathrm{C}$. Different biochars were produced at two absolute pressures $(0.1$ and 0.5 $\mathrm{MPa})$ and using two different carrier gases $\left(\mathrm{N}_{2}\right.$ and $\mathrm{CO}_{2}$ ). The resulting biochar did not show appropriate textural properties to be used as an adsorbent or catalyst. According to Lillo-Ròdenas et al [1], the optimal pore size for the adsorption of volatile organic compounds (VOC) is around 0.7 $\mathrm{nm}$. Therefore, in order to improve their specific surface area and pore size distribution, the biochar was physically and chemically activated.

The specific aim of the present study is to develop a renewable and low-cost biochar-based material to be used as enhancer of pyrolysis vapor cracking. Given that pyrolysis vapors are usually complex mixtures of more than a hundred compounds, a mixture of four model compounds has been chosen as pyrolysis vapor model in order to preliminary investigate the performance of the biochar materials in an easier way. A mixture of acetone, acetic acid, ethanol, and eugenol was finally chosen for this purpose. All of the chosen compounds are major components present in the condensable fraction of the effluent stream coming from slow pyrolysis of biomass [2]. Acetone and acetic acid are resulting products of the degradation of the cellulose and hemicellulose, whereas eugenol and ethanol are lignin-derived compounds.

\section{Experimental Section}

Physical activation consisted of heating biochar up to $800{ }^{\circ} \mathrm{C}$ in a $\mathrm{CO}_{2}$-containing atmosphere [3]. Two different $\mathrm{CO}_{2}$ concentrations $(50 \%$ vol. and $100 \%$ vol.) at constant soaking time $\left(1 \mathrm{~h}\right.$ at $\left.800{ }^{\circ} \mathrm{C}\right)$ were chosen to evaluate the influence of the percentage of burn-off (which is closely related to extent of the reverse Boudouard reaction) on the properties of the biochar-based activated carbon.

During the chemical activation process, biochar was impregnated with an aqueous solution of $\mathrm{K}_{2} \mathrm{CO}_{3}$ (at a mass ratio of 1) and subsequently dried and heated up to $700{ }^{\circ} \mathrm{C}$ under a $\mathrm{N}_{2}$ atmosphere [4].

The textural properties of the produced adsorbents will be evaluated from the adsorption isotherms of $\mathrm{CO}_{2}$ at $273 \mathrm{~K}$ and $\mathrm{N}_{2}$ at $77 \mathrm{~K}$.

The assessment of the performance of biochar-based catalyst is currently under progress. The experimental device is based on a fixed-bed reactor (10 mm internal diameter of $30 \mathrm{~mm}$ length). An equal mass mixture of four model compounds (ethanol, acetic acid, acetone and eugenol) is added to a gas stream $\left(\mathrm{N}_{2}\right)$ by means of an HPLC pump. Using this experimental set up, we are able to study the influence of the gas hourly space velocity (GHSV), absolute pressure (in the range of $0.1-1.0$ $\mathrm{MPa})$ and bed temperature $\left(650-750{ }^{\circ} \mathrm{C}\right)$. The effluent gas stream is analyzed using a dual channel $\mu$-GC analyzer (Agilent 490) and a continuous gas analyzer (ABB EL3020), which measures continuously the volumetric concentration of $\mathrm{CO}$, $\mathrm{CO}_{2}$, and $\mathrm{CH}_{4}$.

\section{Preliminary results}

Until now some biochars have already been produced and are currently been tested in the bench scale plant described above. The samples of biochar, produced with $\mathrm{N}_{2}$ as a carrier gas and at atmospheric pressure, have already been physically activated with $\mathrm{CO}_{2}$.

Preliminary experiments are being developed to study the effects of the operative conditions and 
optimize them. The first results are very promising, since both the amount of total produced gas and the individual yields of $\mathrm{H}_{2}$ and $\mathrm{CO}$ increased when an activated biochar was employed, if compared with the products obtained using an inert material (i.e. silica sand) or no-activated biochar.

Once the study of the catalytic cracking has been completed, the behavior of biochar-based materials for dry and steam reforming will also be investigated.

\section{Acknowledgements}

This project has received funding from the European Union's Horizon 2020 research and innovation programme under the Marie Skłodowska-Curie grant agreement No 721991.

\section{References}

[1] M. A. Lillo-Ròdenas, A. J. Fletcher, K. M. Thomas, D. Cazorla-Amoròs, and A. Linares-Solano, "Competitive adsorption of a benzene-toluene mixture on activated carbons at low concentration," Carbon N. Y., vol. 44, no. 8, pp. 1455-1463, 2006.

[2] M. Fu, W. Qi, Q. Xu, S. Zhang, and Y. Yan, "Hydrogen production from bio-oil model compounds dry (CO2) reforming over $\mathrm{Ni} / \mathrm{A} 12 \mathrm{O} 3$ catalyst," Int. J. Hydrogen Energy, vol. 41, no. 3, pp. 1494-1501, 2016.

[3] W. J. Liu, H. Jiang, and H. Q. Yu, "Development of Biochar-Based Functional Materials: Toward a Sustainable Platform Carbon Material," Chem. Rev., vol. 115, no. 22, pp. 12251-12285, 2015.

[4] W. T. Tsai, C. Y. Chang, S. Y. Wang, C. F. Chang, S. F. Chien, and H. F. Sun, "Preparation of activated carbons from corn cob catalyzed by potassium salts and subsequent gasification with $\mathrm{CO} 2$," Bioresour Technol., vol. 78, no. 2, pp. 203-208, 2001. 